\title{
Acute neuroinflammation provokes intracellular acidification in mouse hippocampus
}

Anna A. Tyrtyshnaia ${ }^{1,2}$, Larisa V. Lysenko ${ }^{1,3}$, Francisco Madamba'1, Igor V. Manzhulo², Maxim Y. Khotimchenko ${ }^{2}$ and Alexander M. Kleschevnikov ${ }^{1,2^{*}}$

\begin{abstract}
Background: Maintaining pH levels within the physiological norm is an important component of brain homeostasis. However, in some pathological or physiological conditions, the capacity of the $\mathrm{pH}$ regulatory system could be overpowered by various factors resulting in a transient or permanent alteration in $\mathrm{pH}$ levels. Such changes are often observed in pathological conditions associated with neuroinflammation. We hypothesized that neuroinflammation itself is a factor affecting pH levels in neural tissue. To assess this hypothesis, we examined the effects of acute LPS-induced neuroinflammation on intra- and extracellular $\mathrm{pH}$ ( $\mathrm{pHi}$ and $\mathrm{pHo}$ ) levels in the CA1 region of mouse hippocampus.
\end{abstract}

Methods: Acute neuroinflammation was induced using two approaches: (1) in vivo by i.p. injections of LPS (5 mg/kg) and (2) in vitro by incubating hippocampal slices of naïve animals in the LPS-containing media $\left(1 \mu \mathrm{g} / \mathrm{mL}, 1 \mathrm{~h}\right.$ at $\left.35^{\circ} \mathrm{C}\right)$. Standard techniques were used to prepare hippocampal slices. pHi was measured using ratiometric $\mathrm{pH}$-sensitive fluorescent dye BCECF-AM. pHo was assessed using calibrated pH-sensitive micropipettes. The presence of neuroinflammation was verified with immunohistochemistry (IL-1 $\beta$ and Iba1) and ELISA (IL-1 $\beta$ and TNF-a).

Results: A significant reduction of pHi was observed in the slices of the LPS-injected 3-month-old (LPS 7.13 \pm 0.03 ; Sal 7.22 $\pm 0.03 ; p=0.043, r=0.43$ ) and 19-month-old (LPS $6.78 \pm 0.08 ;$ Sal 7.13 $\pm 0.03 ; p=0.0001, r=0.32$ ) mice. In contrast, the levels of pHo within the slice, measured in 19-month-old animals, were not affected (LPS 7.27 $\pm 0.02 ;$ Sal 7.26 \pm 0.02 ; $p=0.6, r=0.13$ ). A reduction of pHi was also observed in the LPS-treated slices during the interval $3.5-7 \mathrm{~h}$ after the LPS exposure (LPS $6.92 \pm 0.07$; Veh 7.28 $\pm 0.05 ; p=0.0001, r=0.46$ ).

Conclusions: Acute LPS-induced neuroinflammation results in a significant intracellular acidification of the CA1 neurons in mouse hippocampus, while the pHo remains largely unchanged. Such changes may represent a specific protective reaction of neural tissue in unfavorable external conditions or be a part of the pathological process.

Keywords: Acidification, Extracellular pH, Intracellular pH, BCECF, Neuroinflammation, LPS, IL-1ß, Iba1, Hippocampus, Mice

\section{Background}

Maintaining brain acidity within the physiological norm is an important component of homeostasis in the central nervous system. $\mathrm{pH}$ levels affect the conformation of proteins and other biological molecules, thereby regulating the efficiency and functional activity of enzymes,

\footnotetext{
*Correspondence: akleschevnikov@ucsd.edu

'Department of Neurosciences, University of California San Diego, 9500

Gilman Drive, La Jolla, CA 92093, USA

${ }^{2}$ School of Biomedicine, Far Eastern Federal University, Sukhanova 8,

Vladivostok 690950, Russian Federation

Full list of author information is available at the end of the article
}

receptors, and ion channels [1-4]. Accordingly, enzymatic reactions, ion transport, and protein and DNA synthesis, as well as the physiological integrity of cells, depend on the $\mathrm{pH}$ levels in neural tissue $[1,4-6]$. To ensure the functional stability of neural tissue, a powerful multicomponent $\mathrm{pH}$ regulatory system has evolved $[3,7]$. However, the capacity of this system can become overwhelmed during critical conditions caused by various pathological or even physiological factors resulting in a transient or permanent alternation in brain acidity [7]. 
Changes in regional $\mathrm{pH}$ levels in the brain have been observed in a number of neurological and neurodegenerative disorders. Thus, acidic $\mathrm{pH}$ shifts were observed in the basal ganglia and the whole brain in bipolar disorder $[8,9]$. Hippocampal $\mathrm{pH}$ levels were reduced in mild cognitive impairment (MCI) [10] and even in normal aging [11-13]. Interestingly, all these conditions are characterized by increased neuroinflammation $[9,14]$ suggesting that neuroinflammation itself could be a factor affecting neural $\mathrm{pH}$ levels.

To determine whether neuroinflammation is affecting brain acidity, we measured intra- and extracellular $\mathrm{pH}$ levels in mouse hippocampal slices after experimentally induced neuroinflammation. To this end, two approaches were used. First, acute neuroinflammation was induced "in vivo" by a single intraperitoneal injection of bacterial lipopolysaccharides (LPS). Second, neuroinflammation was induced "in vitro" by exposing hippocampal slices of naïve animals to the LPS-containing media. We observed that neuroinflammation was accompanied by a significant reduction of intracellular $\mathrm{pH}$ levels in both cases, while the extracellular $\mathrm{pH}$ remained largely unchanged. Thus, acute neuroinflammation may cause significant intracellular acidification in a mouse hippocampus. We speculate that such changes represent a protective reaction, specific for neural tissue, which may restrict neuronal activity, thus reducing the impact of pathological factors on the integrity of neural circuits in unfavorable conditions.

\section{Methods}

\section{Animals}

The experiments were performed on male mice bred on C57BL/6JEi $\times$ C3SnHeSnJ (B6EiC3) genetic background. The animals were housed two to four per cage with a 12-h light-dark cycle and ad lib access to food and water. To reduce stress, the mice were handled for $5 \mathrm{~min}$ once a day during five consecutive days before the experiments. The experiments with in vivo-induced neuroinflammation were performed on 3-month-old $(n=12)$ and 19-month-old $(n=10)$ mice. The experiments with in vitro-induced neuroinflammation were performed on 3month-old $(n=10)$ animals. All experiments were conducted in accordance with the National Institutes of Health guidelines and with an approved protocol from the University of California San Diego (UCSD) Institutional Animal Care and Use Committee.

\section{Slice preparation}

The animals were anesthetized with isoflurane before decapitation. The brain was quickly removed and immersed for $2 \mathrm{~min}$ in ice-cold artificial cerebrospinal fluid (ACSF) containing $119 \mathrm{mM} \mathrm{NaCl}, 2.5 \mathrm{mM} \mathrm{KCl}, 2.5 \mathrm{mM} \mathrm{CaCl}$, $1.3 \mathrm{mM} \mathrm{MgSO}_{4}, 1 \mathrm{mM} \mathrm{NaH}_{2} \mathrm{PO}_{4}, 26 \mathrm{mM} \mathrm{NaHCO}_{3}$, and $10 \mathrm{mM}$ glucose, osmolarity $310 \mathrm{mOsm}$, continuously bubbled with carbogen $\left(95 \% \mathrm{O}_{2}, 5 \% \mathrm{CO}_{2}\right)$, at $\mathrm{pH}$ 7.4. The hippocampus was extracted and cut in ice-cold ACSF with a vibratome (Leica 1000) into 350- $\mu \mathrm{m}$-thick slices, which were allowed to recover in oxygenated ACSF at $35{ }^{\circ} \mathrm{C}$ for $15 \mathrm{~min}$ and then at room temperature for at least $1 \mathrm{~h}$.

\section{Experimental design}

The effects of acute neuroinflammation on neural acidity were measured in mouse hippocampal slices using two approaches.

\section{"In vivo"-induced neuroinflammation}

The mice were i.p. injected with either LPS $(5 \mathrm{mg} / \mathrm{kg}$, $200 \mu \mathrm{L})$ or vehicle $(0.9 \% \mathrm{NaCl}, 200 \mu \mathrm{L})$. Hippocampal slices were prepared $3 \mathrm{~h}$ after the injections, allowed to recover, and loaded with BCECF-AM $(5 \mu \mathrm{M}, 30 \mathrm{~min}$ at $35{ }^{\circ} \mathrm{C}$ ). After that, the slices were washed three times in fresh ACSF and stored for 1-6 h in regular ACSF (RT) before the $\mathrm{pH}$ measurements.

\section{"In vitro"-induced neuroinflammation}

Neuroinflammation was induced by incubating hippocampal slices of naive animals in the LPS-containing media. To this end, the slices were prepared as described, allowed to recover for $50 \mathrm{~min}$, and then transferred for $1 \mathrm{~h}$ in small $(2 \mathrm{~mL})$ individual vales filled with ACSF containing either LPS $(1 \mu \mathrm{g} / \mathrm{mL}$, Escherichia coli 0111:B4, cat. \# L4391, Sigma-Aldrich, St. Louis, MO) or vehicle. The solution temperature was constantly monitored with a thermocouple thermometer and kept at $35^{\circ} \mathrm{C}$. To ensure proper oxygenation of the media, the vales were covered with plastic leads and the air/medium surface was constantly overblown by warm fresh carbogen. After this procedure, the slices were washed three times for $5 \mathrm{~min}$ in fresh oxygenated warm ACSF and loaded with BCECFAM $\left(5 \mu \mathrm{M}, 30 \mathrm{~min}\right.$ at $\left.35^{\circ} \mathrm{C}\right)$. After the staining, the slices were washed three times and stored in regular ACSF at $25^{\circ} \mathrm{C}$ for $0-5 \mathrm{~h}$ before the $\mathrm{pH}$ measurements.

\section{Measurements of $\mathrm{pH}$ levels}

Extracellular $\mathrm{pH}$ ( $\mathrm{pHo}$ ) was measured using $\mathrm{pH}$-sensitive micropipettes fabricated as previously described [15]. Briefly, concentric $\mathrm{pH}$-sensitive micropipettes were fabricated from two thin-walled borosilicate glass capillaries of different diameters. The wider capillary had an OD of $2.0 \mathrm{~mm}$ and an ID of $1.6 \mathrm{~mm}$ (A-M Systems 6185). The inner surface of this capillary was covered with $N, N$ dimethyltrimethylsilylamine (Fluka 41720) and filled with proton-selective cocktail (Fluka 95291), which was incorporated into the capillary tip by suction to form a 100 - to $200-\mu \mathrm{m}$ column. The inner micropipette was pulled using a thin-walled glass capillary with an OD of $1.2 \mathrm{~mm}$ and an ID of $0.9 \mathrm{~mm}$ (A-M Systems 6160) to 
produce a tip diameter of $\sim 1 \mu \mathrm{m}$. The micropipette was then backfilled with a solution of $3 \mathrm{M} \mathrm{KCl}$ containing $50 \mathrm{mM} \mathrm{K} / \mathrm{Na}$ phosphate buffer at $\mathrm{pH}$ 7.4. The smallerdiameter micropipette was threaded within the larger barrel and through the column of the ion exchanger, until its end was $\sim 10 \mu \mathrm{m}$ from the tip of the outer micropipette. The inner barrel was then secured around the opening of the outer barrel using wax. Electrical contact to the $\mathrm{KCl}$ solution of the inner pipette was made with a silver-silver chloride junction. Freshly fabricated $\mathrm{pH}$-sensitive micropipettes were calibrated using phosphate buffers with different predetermined $\mathrm{pH}$ levels. Because the registered voltage is proportional to the $\mathrm{pH}$ levels for such micropipettes [15], two solutions with $\mathrm{pH} 6.9$ and 7.4 were used for the calibration. A representative calibration curve is shown in Additional file 1: Figure S1A. The sensitivity of individual micropipettes $(K)$ varied from 56 to $64 \mathrm{mV} / \mathrm{pH}$, with the average value of $60.9 \pm 1.0 \mathrm{mV} / \mathrm{pH}$ unit.

When measured in slice preparations, the level of $\mathrm{pHo}$ varies as a function of distance from the slice surface [16-18]. To measure such pHo profiles, the tip of a calibrated $\mathrm{pH}$-sensitive micropipette was first placed at the "starting" position of $200 \mu \mathrm{m}$ above the slice, at which position $\mathrm{pHo}=$ pHacsf, and then moved down by $20-\mu \mathrm{m}$ steps, once in $5 \mathrm{~s}$, till the position of $180 \mu \mathrm{m}$ below the slice surface (Additional file 1: Figure S1B, "Vp," see also a schematic on Fig. 3a). After recording with the pHsensitive micropipette, the same procedure was repeated with a regular microelectrode to record the corresponding changes in voltage (Additional file 1: Figure S1B, "Ve"). The pHo levels were computed as $\mathrm{pHo}=$ pHacsf $(\mathrm{Vp}-\mathrm{Ve}) / K$ (Additional file 1: Figure S1C).

Intracellular $\mathrm{pH}(\mathrm{pHi})$ was measured using ratiometric pH-sensitive dye BCECF-AM (B1170, Thermo Fisher Scientific, Waltham, MA). To this end, hippocampal slices were loaded with BCECF-AM $(5 \mu \mathrm{M}, 30 \mathrm{~min}$ at $35{ }^{\circ} \mathrm{C}$ ), washed in fresh warm ACSF three times for $5 \mathrm{~min}$, and allowed for BCECF-AM processing at RT for additional $0.5-1.5 \mathrm{~h}$ before the $\mathrm{pH}$ measurements. For the measurements, one of the BCECF-loaded slices was transferred into the submerged recording chamber superfused with ACSF at a constant rate of $2.5 \mathrm{~mL} / \mathrm{min}$ at $32{ }^{\circ} \mathrm{C}$. After a 10 -min stabilization, the slice was excited at 440 and $490 \mathrm{~nm}$ using a LED light source (pE-2, CoolLED, UK), and the fluorescence emitted at $535 \mathrm{~nm}$ was captured using fluorescent microscope BX-51 (Olympus) equipped with the Rolera-XR (QImaging) digital camera. The images were stored on a computer hard drive and used for offline estimation of pHi using MetaMorph (Molecular Devices, USA).

For quantitative evaluation of $\mathrm{pHi}$, calibration with a modified nigericin method [19] was performed at the end of each experiment. To this end, high- $\mathrm{K}^{+}(100 \mathrm{mM})$ solution with nigericin $(5 \mu \mathrm{M})$ was pressure-applied to the slice surface locally for $10 \mathrm{~min}$ through a micropipette (tip diameter $\sim 10 \mu \mathrm{m}$ ) placed $\sim 20 \mu \mathrm{m}$ above the slice, and the $F_{440} / F_{490}$ ratios were measured in ACSF$\mathrm{pH}_{1}(\mathrm{pH}=7.4)$ and ACSF- $\mathrm{pH}_{2}(\mathrm{pH}=6.6)$. Local $\mathrm{pHo}$ levels in neurons' vicinity were measured with a $\mathrm{pH}$ sensitive micropipette, and the dependence of the $F_{440} /$ $F_{490}$ ratio from the $\mathrm{pHi}$ was computed. All healthylooking CA1 pyramidal neurons within the field of view were selected as regions of interest (ROI) using DIC images. The ROI areas varied from 280 to $520 \mu \mathrm{m}^{2}$. The results were averaged for all ROI in the locus.

\section{Immunohistochemistry \\ In vivo study}

The mice were deeply anesthetized with isoflurane and transcardially perfused for 1 min with $0.9 \% \mathrm{NaCl}$ $(10 \mathrm{~mL})$ and then for $10 \mathrm{~min}$ with $4 \%$ paraformaldehyde in $0.1 \mathrm{M}$ phosphate-buffered saline (PBS), $\mathrm{pH}$ 7.4. The brains were removed, kept in the same fixative for $24 \mathrm{~h}$, washed, and then transferred to a $30 \%$ sucrose solution for a day. Thereafter, the samples were transferred to a Neg 50 (Thermo Scientific) medium for another day and then $30-\mu \mathrm{m}$ sagittal sections were prepared with a cryostat microtome (HM525, Thermo Scientific). Free-floating sagittal sections were pre-incubated in $5 \%$ nonfat milk in PBS and then incubated overnight at $4{ }^{\circ} \mathrm{C}$ with rabbit IL$1 \beta$ (ab9722, Abcam, 1:500) or Iba1 (ab107159, Abcam, 1:500) primary antibody. The sections were then rinsed in PBS (10 min, three changes) and incubated for $2 \mathrm{~h}$ at room temperature with peroxidase mouse anti-rabbit IgG (PI-1000, Vector Laboratories, 1:200). After rinsing with PBS (10 min, three changes), the sections were incubated with diaminobenzidine solution (SK-4105, ImmPACT ${ }^{\mathrm{Tm}}$ DAB Peroxidase Substrate) for $2 \mathrm{~min}$ at room temperature. Following further rinsing, the sections were mounted on microscope glass slides and coverslipped with VectaMount Permanent Mounting Medium (H-5000, Vector Laboratories).

Microphotographs were captured and stored as TIFF files. The images were processed and analyzed using ImageJ (NIH, USA). Quantification of IL-1 $\beta$ - and Iba1immunopositive cells was performed on a one-in-six series of labeled sections. The total number of IL-1 $\beta$ - or Iba1-positive cells in the CA1 region was computed by an operator blinded to the sections' identity. The number of cells per $1 \mathrm{~mm}^{3}$ was computed.

\section{In vitro study}

To determine whether or not in vitro exposure of hippocampal slices to LPS activated pro-inflammatory signaling, hippocampal slices were prepared as described for $\mathrm{pH}$ measurements, allowed for 1 -h recovery, and then placed in saline-ACSF or $1 \mu \mathrm{g} / \mathrm{mL}$ LPS-ACSF. After 
$30 \mathrm{~min}$ of drug exposure, the slices were incubated in ACSF for additional 2-7 $\mathrm{h}$ and then fixed in $4 \%$ paraformaldehyde in $0.1 \mathrm{M}$ PBS for $12 \mathrm{~h}$. After that, the slices were washed five times for $5 \mathrm{~min}$, and $50-\mu \mathrm{m}$-thick sections were made from the central part of the $350-\mu \mathrm{m}$ slices using a vibratome (Leica 1000). Immunohistochemistry for IL-1 $\beta$ and evaluation of the data were performed as described above.

\section{Enzyme-linked immunosorbent assay}

Enzyme-linked immunosorbent assay (ELISA) was used to quantify the hippocampal levels of IL-1 $\beta$ and TNF- $\alpha$. In the in vivo experiments, isoflurane-anesthetized mice were decapitated $3 \mathrm{~h}$ after the LPS injection. Within 1 min after the decapitation, the hippocampi were extracted, quickly frozen, and stored at $-70{ }^{\circ} \mathrm{C}$ until use. In the in vitro experiments, the slices collected after the LPS or saline exposure were used. Mouse IL-1 $\beta$ ELISA (ab100705, Abcam) and TNF- $\alpha$ ELISA (ab100747, Abcam) kits were used according to the manufacturer's recommendations. Neural tissue was homogenized on ice in the extraction buffer recommended by the manufacturer $(100 \mathrm{mM}$ Tris, $\mathrm{pH} 7.4,150 \mathrm{mM} \mathrm{NaCl}, 1 \mathrm{mM}$ EGTA, 1 mM EDTA, $1 \%$ Triton X-100, $0.5 \%$ sodium deoxycholate) with $1 \mathrm{mg} / \mathrm{mL}$ of protease inhibitor cocktail (cOmplete, Sigma-Aldrich) and $0.01 \mathrm{mg} / \mathrm{mL}$ of phosphatase inhibitor cocktail (P5726, Sigma-Aldrich). The protein concentrations were determined using a BCA protein assay kit (Pierce, Rockford, IL). The absorbance at $450 \mathrm{~nm}$ was measured with an iMark Microplate Absorbance Reader (Bio-Rad).

\section{Statistical analysis}

Data are shown as mean \pm SEM. " $n$ " represents the number of images for the pHi measurements, the number of slices for the pHo and IHC measurements, and the number of animals for ELISA. All tests were performed using GraphPad software. All parameters were examined for normality of distributions using the KolmogorovSmirnov test. Depending on whether or not the experimental data showed normal distributions, the nonparametric Mann-Whitney rank sum test or one-way analyses of variance (ANOVAs) were used. The differences were considered significant at $p<0.05$.

\section{Results}

The effects of acute neuroinflammation on neural $\mathrm{pH}$ levels were assessed in mouse hippocampal slices using two approaches. First, neuroinflammation was induced in vivo by i.p. injections of LPS, while vehicle-injected littermate mice were used for controls. Second, neuroinflammation was induced in vitro by exposing hippocampal slices of naïve animals to the LPS-containing media. Adjacent slices from the same animal were treated with vehicle (saline) and used for controls. The presence of neuroinflammation was confirmed by immunostaining, for IL- $1 \beta$ and Iba1, and ELISA, for IL- $1 \beta$ and TNF- $\alpha$.

\section{In vivo-induced neuroinflammation}

Intraperitoneal injection of bacterial lipopolysaccharides represents an effective experimental approach to induce neuroinflammation in the mammalian brain. Profound activation of pro-inflammatory markers can usually be observed in a few hours after LPS injections (e.g., [20, 21]). We injected LPS or vehicle in 3- and 19-month-old mice and examined neuroinflammation and neural acidity in hippocampal slices prepared $3 \mathrm{~h}$ after the injections. To determine whether the LPS injections induced neuroinflammation, we first used immunohistochemistry to measure the densities of IL-1 $\beta$ - and Iba1-immunopositive neurons in the CA1 region (Fig. 1a). As expected, the densities of both IL-1 $\beta$ - and Iba1-immunopositive cells were significantly increased in the slices from the LPSinjected 3-month-old (IL-1 $\beta F=114.4, p=0.0001$; Iba1 $F=34.5, p=0.0001)$ and 19-month-old (IL-1 $\beta F=424.8$, $p=0.0001$; Iba1 $F=53.5, p=0.0001$ ) mice (Fig. 1a). Next, ELISA was used to assess the concentrations of IL- $1 \beta$ and TNF- $\alpha$. Again, the concentrations of these neuroinflammatory markers were increased in the slices from both 3-month-old (IL-1 $\beta p=0.029, r=0.82$; TNF$\alpha p=0.029, r=0.82$ ) and 19-month-old (IL-1 $\beta p=0.029$, $r=0.82$; TNF- $\alpha p=0.029, r=0.82$ ) LPS-injected mice. Thus, in our experimental conditions, i.p. injections of LPS resulted in effective induction of neuroinflammation.

To assess the effects of neuroinflammation on brain acidity, we first measured $\mathrm{pHi}$ in the CA1 neurons. To this end, freshly prepared hippocampal slices were loaded with BCECF-AM and the pHi was measured between 3.5 and $7 \mathrm{~h}$ after the LPS injections. As can be seen from the representative images (Fig. 2a), the $F_{440} /$ $F_{490}$ ratio was considerably reduced in the slices from the LPS-injected mice suggesting an acidification of the intracellular compartments. These changes were assessed quantitatively after calibrating the $F_{440} / F_{490}$ ratio using a modified nigericin method. The averaged data between 3.5 and $7 \mathrm{~h}$ after LPS injections showed a significant reduction of $\mathrm{pHi}$ in the LPS vs. saline group in both 3-month-old $(F=4.64, p=0.04)$ and 19-monthold $(F=21.19, p=0.0001)$ mice (Fig. 2b). Thus, the induced neuroinflammation was accompanied by significant intracellular acidification in the CA1 region.

Changes in pHi could be generated either by an accumulation of lactate and other acidic products of metabolism or by transmembrane ionic fluxes via ionic transporters and channels. If changes in transmembrane fluxes are involved, it is expected that $\mathrm{pHi}$ and $\mathrm{pHo}$ would change in the opposite direction and, therefore, intracellular acidification would be accompanied by an 


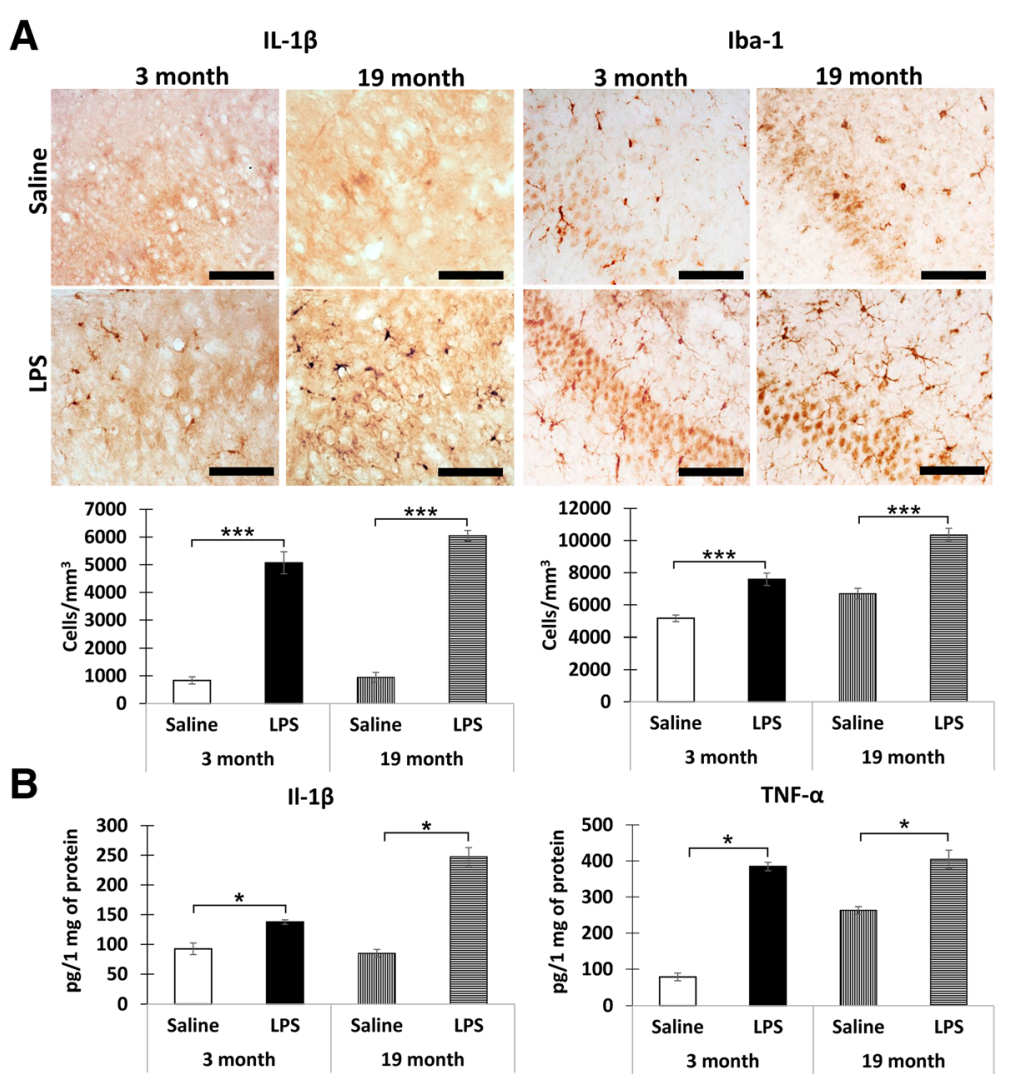

Fig. 1 i.p. injection of LPS-induced neuroinflammation in both young and old mice. a Top: representative examples of IL-1 $\beta$ and Iba1 immunostaining in hippocampal slices from the saline- and LPS-injected mice. The mouse age is indicated above the images. Bottom graphs: quantification of the cell density. Mean $\pm \mathrm{SEM}, n=10$ per group, ${ }^{* * *} p=0.0001$. b Levels of IL-1 $\beta$ and TNF-a measured by ELISA. Mean $\pm \mathrm{SEM}, n=4$ per group, ${ }^{*} p<0.03$

extracellular alkalization. On the contrary, if the major cause of pHi changes is metabolic acidosis, pHi and pHo would both show an acidic shift. To assess which of these mechanisms were likely to contribute to the intracellular acidification during neuroinflammation, we measured $\mathrm{pHo}$ in the $\mathrm{CA} 1$ region using $\mathrm{pH}$-sensitive micropipettes. These measurements were performed on 19-month-old mice, which had showed greater $\mathrm{pHi}$ changes. Previously, it was observed that pHo changes gradually as a function of the distance from the slice surface $[17,18]$. To measure pHo profiles, we placed the tip of the $\mathrm{pH}$-sensitive micropipette $200 \mu \mathrm{m}$ above the slice surface and then moved the tip downwards in $20-\mu \mathrm{m}$ increments until it was located $180 \mu \mathrm{m}$ below the slice surface (Fig. 3a). A representative time course of the pHo changes during an experiment is shown in Fig. 3b. pHo levels showed step-like changes corresponding to the incremental micropipette movements with relative stability between the movements (Fig. 3b insert, between the arrows). The averaged values for such stable periods were taken as the pHo measure at the corresponding distances from the slice surface. To quantify the effects of neuroinflammation, pHo profiles were averaged for the LPS and vehicle groups (Fig. 3c). For all distances, there was no significant difference between the groups. We concluded that acute neuroinflammation had no effect on pHo in the CA1 region of mouse hippocampus.

Thus, acute neuroinflammation, evoked by i.p. injections of LPS, resulted in significant intracellular acidification without changing the extracellular $\mathrm{pH}$ in mouse hippocampus.

\section{In vitro-induced neuroinflammation}

Next, the effects of in vitro-induced neuroinflammation on $\mathrm{pH}$ levels were examined in 3-month-old mice. A notable advantage of in vitro approaches is the possibility for a side-by-side comparison of the slices from the same animal. Such an experimental arrangement allows us to reduce or eliminate the variability caused by individual differences in the animal health, sensitivity to exogenous compounds, etc. To test the feasibility of an in vitro approach to induce neuroinflammation, we first measured the density of IL- $1 \beta$-positive cells in the CA1 region of slices treated with either LPS $(1 \mu \mathrm{g} / \mathrm{mL})$ or vehicle (Fig. 4a, b). In the LPS-treated slices, the density of IL-1 $\beta$-positive cells showed a trend for an increase soon 


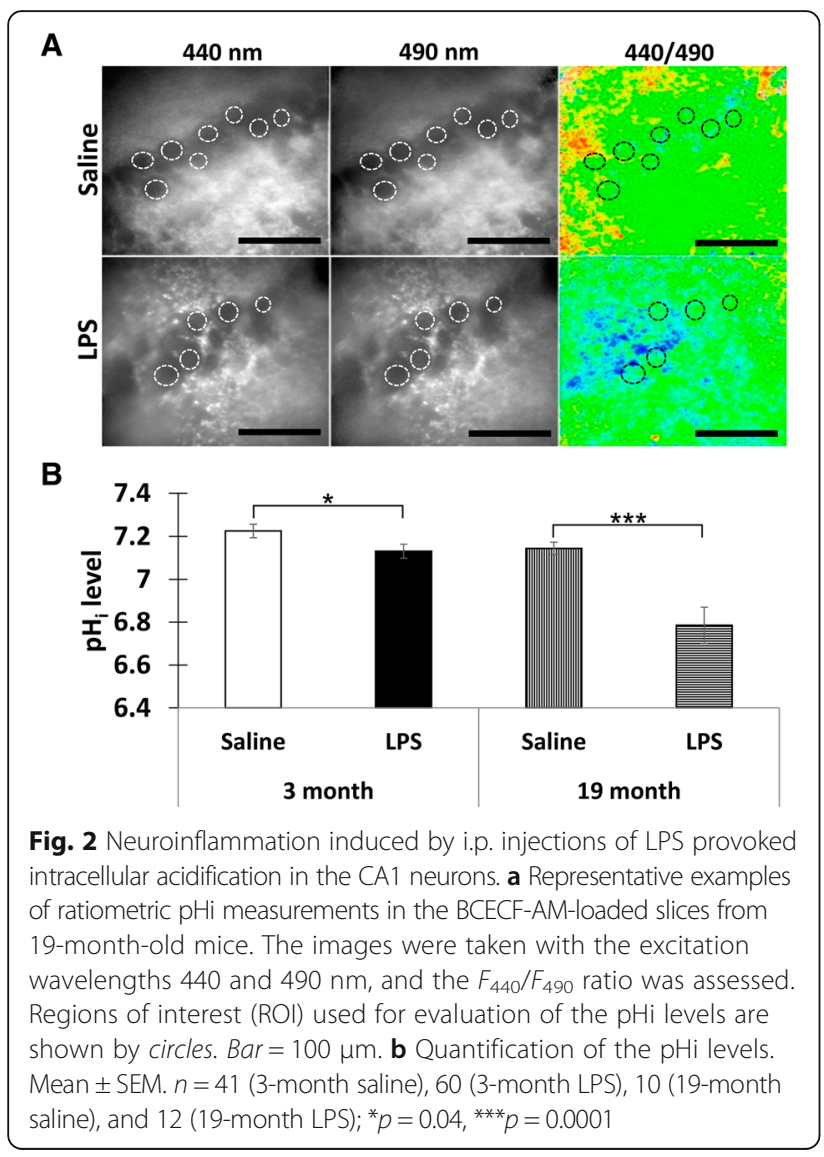

after the LPS exposure (2-3.5 h) and increased significantly during the later periods (3.5-5.5 and 5.5-7 h) after the LPS exposure (Fig. 4b). Such changes in the density of IL-1 $\beta$-positive cells correspond well with the known time course of neuroinflammatory markers during acute neuroinflammation $[20,21]$. In the vehicle-treated slices, the density of IL-1 $\beta$ cells was not altered until at least $5.5 \mathrm{~h}$ after the treatment and increased only slightly during the last period, 5.5-7 h after the treatment (Fig. 4b). Such an increase could reflect a non-specific inflammation caused by tissue damage during the slice preparation. In order to further verify the induction of neuroinflammation, ELISA was used to measure the levels of IL-1 $\beta$. Again, the levels of this neuroinflammatory marker were significantly increased in the LPS-treated slices compared to the vehicletreated slices (Fig. 4c). Thus, in vitro incubation in the LPS-containing media effectively activated neuroinflammatory signaling in mouse hippocampal slices.

To measure the effects of the in vitro-induced neuroinflammation on pHi levels, adjacent hippocampal slices were exposed to either LPS- or vehicle-containing media and then loaded with BCECF-AM. After an additional incubation period of $1-6 \mathrm{~h}$, the slices were transferred to the recording chamber for the pHi measurements. Each slice was used for a measurement at a single time point after the treatment. Figure $5 \mathrm{a}$ illustrates the $\mathrm{pHi}$ measurements in the slices incubated $4 \mathrm{~h}$ after the LPS or vehicle exposure. As can be seen from these examples, pHi levels were significantly reduced in the LPS vs. vehicle-treated slices (Fig. 5a). Quantification of the data showed that $\mathrm{pHi}$ was stable during the initial

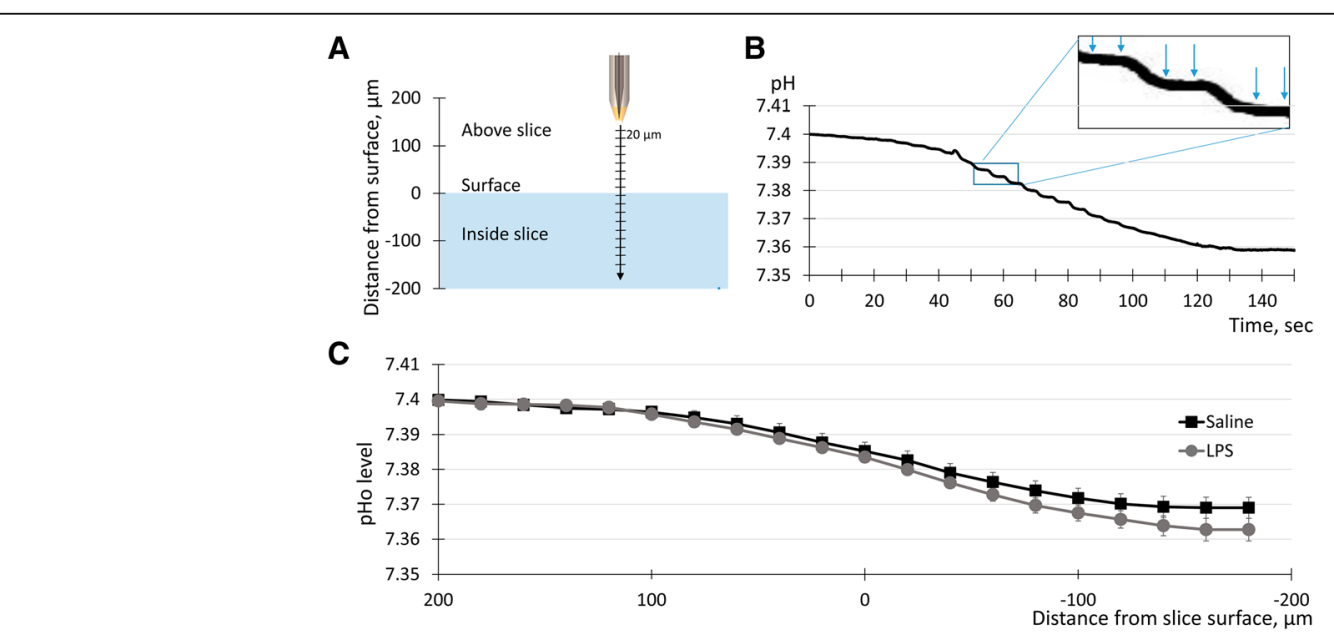

Fig. 3 Neuroinflammation induced by i.p. injections of LPS had no effect on extracellular acidity in the CA1 region. a Schema of the experiment. A pH-sensitive micropipette was sequentially positioned at distances varying from +200 to $-180 \mu \mathrm{m}$ from the slice surface, in steps of $20 \mu \mathrm{m}$, at which pHo levels were measured. $\mathbf{b}$ Time course of pHo changes during a representative experiment. The micropipette was moved to a new position every $5 \mathrm{~s}$. pHo levels changed during the movements but were stable between the movements. Insert: part of the curve at a higher magnification. At each electrode position, pHo levels were averaged for the stable period (between the arrows in the insert). c Averaged data for the $\mathrm{pHo}$ profiles in slices from the saline- and LPS-injected mice. No statistical difference was observed between the saline and LPS groups. LPS: $n=10$; saline: $n=10$ 
A

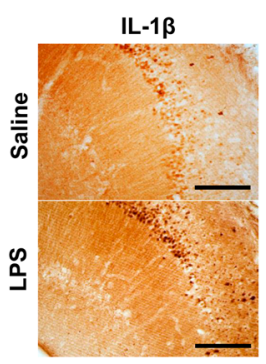

B

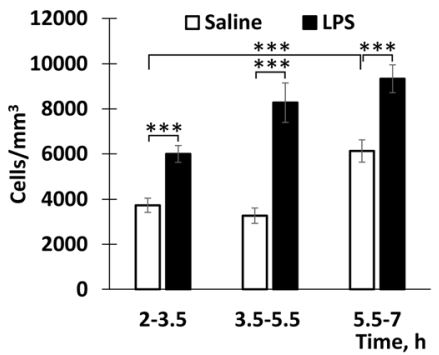

C

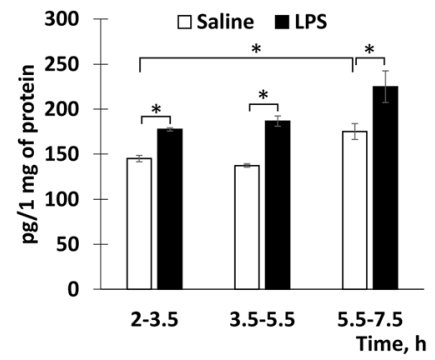

Fig. 4 In vitro exposure of hippocampal slices to the LPS-containing media resulted in profound neuroinflammation. a Representative images of IL-1 $\beta$ immunostaining in slices treated in vitro with the LPS- $(1 \mu \mathrm{g} / \mathrm{mL})$ or vehicle-containing media. Bar $=100 \mu \mathrm{m}$. $\mathbf{b}$ Quantification of the data for IL-1 $\beta$ immunostaining. The mean densities of IL-1 $\beta$-positive cells at different time intervals after the LPS or vehicle exposure. Mean \pm SEM, $n=10$, *** $p=0.0001$. $\mathbf{c}$ Levels of IL-1 $\beta$ measured by ELISA. Mean \pm SEM, $n=4$ per group, ${ }^{*} p<0.03$

period (2-3.5 h) and then significantly reduced (Fig. 5b). Importantly, the most significant pHi reduction was observed for the period 3.5-5.5 h after the LPS exposure, during which the neuroinflammation was observed only in the LPS but not the vehicle-treated slices (see Fig. 4b). Averaged for the total 3.5-7-h period, pHi levels were in Veh 7.29 \pm 0.05 ; in LPS $6.92 \pm 0.07$, thus showing a difference of $\sim 0.36 \mathrm{pH}$ units $(p=0.0001, r=0.46)$. These results show that neuroinflammation reduces $\mathrm{pHi}$ levels not only after in vivo injections of LPS but also after exposing the slices to LPS in vitro.

\section{Discussion}

Here, we examined the effects of acute LPS-induced neuroinflammation on extra- and intracellular $\mathrm{pH}$ in the CA1 neurons of mouse hippocampus. We observed that

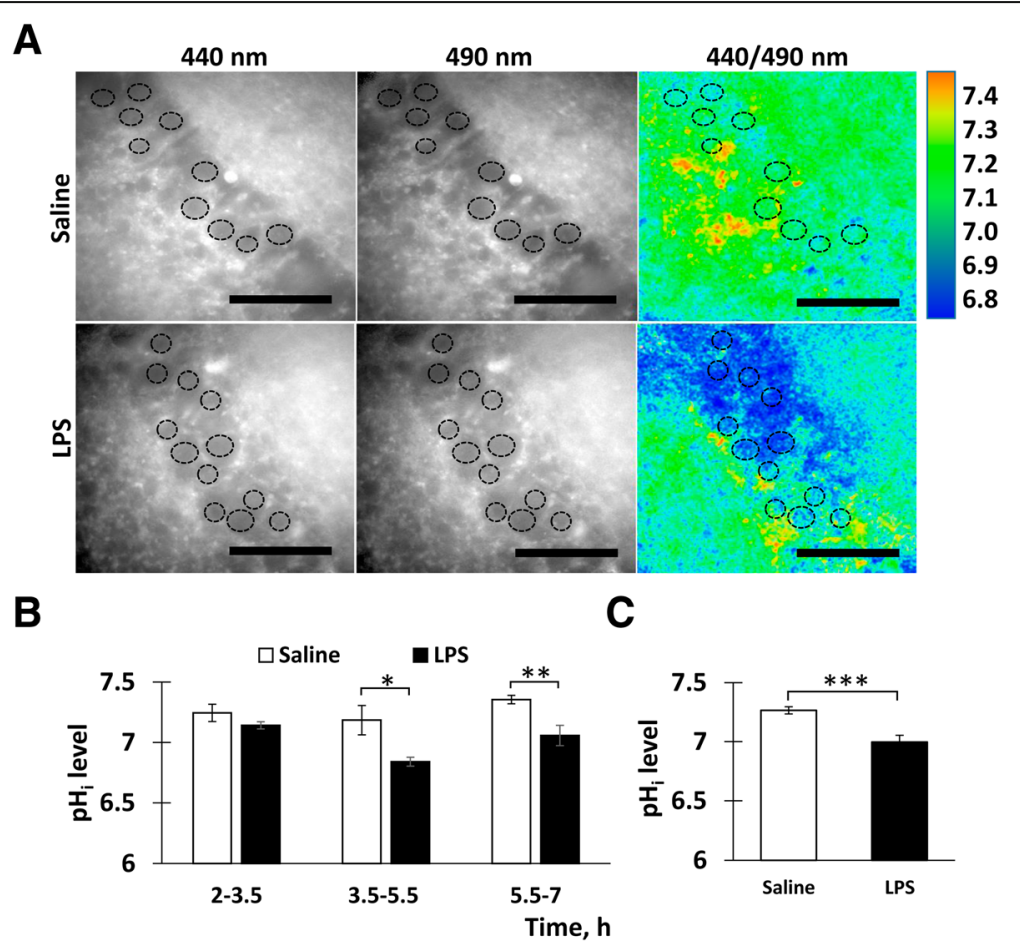

Fig. 5 Neuroinflammation induced by in vitro exposure of hippocampal slices to LPS provoked intracellular acidification in CA1. a Representative images of the BCECF-AM-loaded slices treated with saline or LPS taken with the excitation wavelengths 440 and $490 \mathrm{~nm}$ and the $F_{440} / F_{490}$ ratio. $\mathrm{ROI}$ used for the pHi measurements are marked by circles. Bar $=100 \mu \mathrm{m}$. b Quantification of the data. Averaged pHi levels in the saline- and LPS-treated slices at different post-treatment intervals. Mean \pm SEM; saline: $n=37$ (2-3.5 h), 14 (3.5-5.5 h), and 21 (5.5-7 h); LPS: $n=18$ (2-3.5 h), $22(3.5-5.5 \mathrm{~h})$, and $14(5.5-7 \mathrm{~h}) ;{ }^{*} p=0.03,{ }^{* *} p=0.001$. c Quantification of the data. The data averaged across the entire visible part of the CA1 Str.Pyr. for the period of 3.5-7 h. Mean \pm SEM; saline: $n=72$ (saline) and 54 (LPS); ${ }^{* *} p=0.0001$ 
i.p. injections of LPS, which effectively activated pro-inflammatory signaling, provoked significant intracellular acidification in the CA1 neurons. This change was observed in the absence of notable alterations in the extracellular $\mathrm{pH}$ levels. Furthermore, induction of neuroinflammation by direct exposure of hippocampal slices from the untreated animals to the LPS-containing media also resulted in intracellular acidification. We suggest that such changes may reflect a protective reaction of neural tissue in harsh conditions or represent a part of the pathological process associated with neuroinflammation.

Tertiary structure and, therefore, functional efficiency of many proteins and other biological molecules depends on the $\mathrm{pH}$ of the surrounding tissue. Thus, changes in $\mathrm{pH}$ could modify the efficiency of enzymes [22], receptors [5, 23-26], ionic pumps $[4,27,28]$, and ionic channels [29-31]. Many $\mathrm{pH}-$ sensitive molecules are membrane-bound and involved in the regulation of cellular excitability. As a result, $\mathrm{pH}$ changes may reduce or increase neuronal activity in a tissue-specific manner [4, 32]. In the hippocampus, acidification of neural tissue mostly reduces neural excitability [33, 34]. For example, inhibition of monoamine oxidase-A (MAO-A) by the selective inhibitor moclobemide caused a reduction in pHi by $0.1-0.3 \mathrm{pH}$ units and a suppression of both spontaneous and evoked activity of the CA3 neurons in rodent hippocampus [35]. Similar effects were observed following the inhibition of transmembrane acid extrusion by amiloride, an inhibitor of $\mathrm{Na}^{+} / \mathrm{H}^{+}$exchanger [36], or administration of sulthiame, an inhibitor of carbonic anhydrase [37]. In contrast, a stronger $(0.8-1.0 \mathrm{pH})$ intracellular acidification in crayfish slow flexor muscle fibers increased cellular excitability and provoked all-or-none calcium spikes $[32,38]$. In these studies, however, pHo levels were not assessed and, therefore, it remains uncertain whether the pHi changes alone were responsible for the alteration of cellular excitability. Because downregulation of neuronal excitability in harsh conditions improves cell survival, reduction in $\mathrm{pHi}$ may play a protective role in neurodegenerative and other disorders.

Local acidosis is a characteristic feature of an inflammatory process on the periphery. Acidic $\mathrm{pH}$ shifts were observed in tumors [39], as well as in traumatic and ischemic loci that are characterized by acute or chronic inflammation [40-42]. In the brain, changes in acidity were observed in a number of neurological conditions associated with neuroinflammation, in many of which a reduction of $\mathrm{pH}$ has been observed. For example, intracellular $\mathrm{pH}$ levels were reduced in the frontal lobes, basal ganglia, and whole brain of patients with bipolar disorder [8, 43]. A reduction of
$\mathrm{pH}$ was also observed in human hippocampus during normal aging [11-13]. Likewise, intracellular $\mathrm{pH}$ was reduced in patients with mild cognitive impairment (MCI) [10]. Interestingly, there was no alteration in the $\mathrm{pH}$ levels in patients with Alzheimer's disease (AD) [10]. Moreover, the AD patients showed an increased intracellular $\mathrm{pH}$ in the left hippocampus when compared with the MCI patients [10]. Because all these conditions are characterized by neuroinflammation $[9,44-46]$, it is plausible to suggest that neuroinflammation may contribute to the $\mathrm{pH}$ changes in neurodegenerative disorders. At present, the effects of neuroinflammation on brain acidity have not been yet fully characterized.

We assessed the effects of LPS-induced neuroinflammation on neural $\mathrm{pH}$ levels. In our experiments, control $\mathrm{pHi}$ and pHo levels were about 7.1 and 7.3, respectively. These values are consistent with the measurements observed in other studies $[3,16,47,48]$ indicating that the slices were in good health in our experimental conditions. Acute neuroinflammation, induced by either i.p. injections or direct administration of LPS in the supporting media, resulted in a reduction of $\mathrm{pHi}$ by about $0.1-0.3 \mathrm{pH}$ units leaving pHo unchanged in both cases. It must be noted that because the $\mathrm{pH}$ measurements were performed at temperatures lower $\left(\sim 32^{\circ} \mathrm{C}\right)$ than the physiological norm, neuroinflammation-induced $\mathrm{pH}$ changes in alive animals may differ in magnitude from those observed in our study.

A reduction of $\mathrm{pHi}$ without a notable change in $\mathrm{pHo}$ argues against a purely metabolic cause of the $\mathrm{pH}$ changes during neuroinflammation and suggests the involvement of active regulatory processes. Indeed, during the pathological accumulation of acidic metabolic by-products, such as lactate and $\mathrm{CO}_{2}$, acidic changes should be registered both intra- and extracellularly. For example, nearly equal changes in extra- and intracellular $\mathrm{pH}$ have been observed in hippocampal slices during anoxia [49].

Investigation of the mechanisms involved in the $\mathrm{pH}$ reduction during neuroinflammation was not a subject of this study. However, some mechanisms responsible for these changes could be suggested. The most straightforward mechanism may rely on reduced function of mitochondria [50]. Indeed, release of reactive oxygen and nitrogen species (ROS and RNS) by activated microglia induces oxidative and nitrosative stress leading to mitochondrial impairment $[51,52]$. Moreover, LPS-induced neuroinflammation results in a transient increase in respiratory capacity and ATP production [53], which may also exacerbate the metabolic acidosis. Other mechanisms by which neuroinflammation may affect intracellular $\mathrm{pH}$ may include modulation of acid loaders and/or acid extruders. One hypothetical mechanism may rely on activation of neuronal plasma membrane $\mathrm{Ca}^{2+}$-ATPase (PMCA), a ubiquitous transporter exchanging intracellular $\mathrm{Ca}^{2+}$ for extracellular $\mathrm{H}^{+}$. In 
this scenario, upregulation of IL- $1 \beta$ increases calcium flux through the NMDA receptors [54], thus increasing internal $\mathrm{Ca}^{+2}$, while activated PMCA exchanges the internal $\mathrm{Ca}^{+2}$ on external $\mathrm{H}^{+}$leading to intracellular acidification. In the extracellular space, a reduction in proton concentration could be compensated by an $\mathrm{H}^{+}$efflux from the activated microglia via a $\mathrm{Na}^{+} / \mathrm{H}^{+}$exchanger isoform 1 (NHE1)-dependent mechanism [55, 56]. As a result of this compensation, pHo remains unchanged.

The reduction of intracellular $\mathrm{pH}$ during neuroinflammation may either lead to neuronal death, a part of the pathological process, or represent a protective reaction reducing neuronal activity and the inflammationinduced damage to the neural system. Indeed, a significant $(\mathrm{pH} \sim 0.4)$ intracellular acidification has been observed as an early event in both death receptor-mediated and mitochondria-dependent types of apoptosis (reviewed by [57]). Such changes may lead to activation of caspase-3, which reaches a maximum efficiency at $\mathrm{pH}$ 6.6-6.8 [58] and activation of deoxyribonuclease II [59]. Such reduction in intracellular $\mathrm{pH}$ may also provoke caspase-independent neuronal death [60]. On the other hand, the most notable immediate physiological effect of a moderate $\mathrm{pHi}$ reduction is a suppression of neuronal activity [33, 34]. This suggests that a moderate acidification may play a protective role in some conditions. For example, NMDA-induced superoxide production and neuronal death were prevented by intracellular acidification by as little as $0.2 \mathrm{pH}$ units [61]. A protective role of lactate [62] could also be linked to moderate intracellular acidification [63]. Interestingly, a reduction of intracellular $\mathrm{pH}$ was evoked by several pharmacological compounds, such as antipsychotics (haloperidol, clozapine, ziprasidone), antidepressants (amitriptyline, doxepin, citalopram), anticonvulsants (tiagabine), and other neuroprotective drugs $[35,37,47]$. It was suggested that the intracellular $\mathrm{pH}$ reduction may represent one of the mechanisms responsible for the neuroprotective properties of these compounds [47]. It is therefore feasible that inflammation-induced intracellular acidification may represent a specific protective response of neural tissue diminishing cellular activity and over-activation of neurons in harsh conditions.

\section{Conclusions}

Here, we observed that acute LPS-induced neuroinflammation is accompanied by a moderate intracellular acidification of the CA1 neurons in mouse hippocampus. Presumably, such changes may represent a specific protective reaction of neural tissue during neuroinflammation allowing neurons to survive in unfavorable conditions. Alternatively, the reduction of intracellular $\mathrm{pH}$ may represent a part of the pathological process.

\section{Additional file}

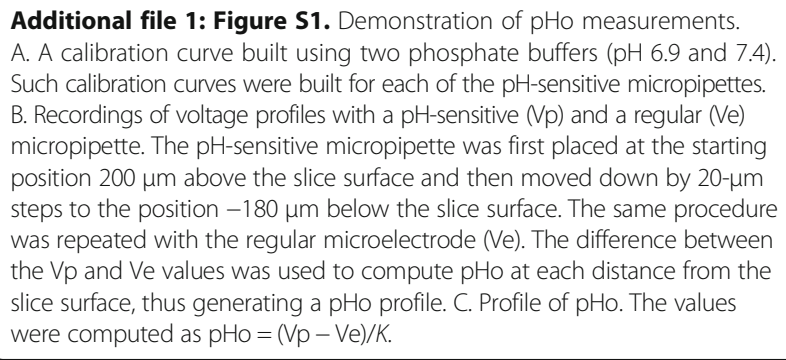

\section{Abbreviations}

ACSF: Artificial cerebrospinal fluid; AD: Alzheimer's disease; LPS: Lipopolysaccharides; MCl: Mild cognitive impairment; $\mathrm{NHE1}: \mathrm{Na}^{+} / \mathrm{H}^{+}$exchanger isoform 1; PBS: Phosphate-buffered saline; $\mathrm{pHi}$ : Intracellular $\mathrm{pH}$; $\mathrm{pHo}$ : Extracellular $\mathrm{pH}$; RNS: Reactive nitrogen species; ROS: Reactive oxygen species

\section{Funding}

The study was supported by the LuMind Foundation, Jerome Lejeune Foundation, and Russian Scientific Fund (project \#14-50-00034).

\section{Availability of data and materials}

Data sharing is not applicable to this article as no datasets were generated or analyzed during the current study.

\section{Authors' contributions}

$A T, M K$, and AK designed the study. AT, LL, FM, and AK performed the $\mathrm{pH}$ measurements. AT and IM performed the immunohistochemical study.

AT and AK wrote the manuscript. All authors read and approved the final manuscript.

\section{Competing interests}

The authors declare that they have no competing interests.

\section{Consent for publication}

Not applicable.

\section{Ethics approval}

All experiments were conducted in accordance with the National Institutes of Health guidelines and with an approved protocol from the University of California San Diego (UCSD) Institutional Animal Care and Use Committee.

\section{Author details}

${ }^{1}$ Department of Neurosciences, University of California San Diego, 9500 Gilman Drive, La Jolla, CA 92093, USA. ${ }^{2}$ School of Biomedicine, Far Eastern Federal University, Sukhanova 8, Vladivostok 690950, Russian Federation.

${ }^{3}$ Academy of Biology and Biotechnology of Southern Federal University, 194/

1 Stachki Str, Rostov-na-Donu 344090, Russian Federation.

Received: 15 June 2016 Accepted: 16 October 2016

Published online: 03 November 2016

\section{References}

1. Casey JR, Grinstein S, Orlowski J. Sensors and regulators of intracellular pH. Nat Rev Mol Cell Biol. 2010;11:50-61.

2. Ziemann AE, Schnizler MK, Albert GW, Severson MA, Howard 3rd MA, Welsh MJ, Wemmie JA. Seizure termination by acidosis depends on ASIC1a. Nat Neurosci. 2008;11:816-22.

3. Chesler M. Regulation and modulation of $\mathrm{pH}$ in the brain. Physiol Rev. 2003:83:1183-221

4. Ruffin VA, Salameh Al, Boron WF, Parker MD. Intracellular pH regulation by acid-base transporters in mammalian neurons. Front Physiol. 2014;5:43.

5. Dietrich CJ, Morad M. Synaptic acidification enhances GABAA signaling. J Neurosci. 2010;30:16044-52.

6. Chiche J, Ilc K, Brahimi-Horn MC, Pouyssegur J. Membrane-bound carbonic anhydrases are key $\mathrm{pH}$ regulators controlling tumor growth and cell migration. Adv Enzyme Regul. 2010;50:20-33. 
7. Obara M, Szeliga M, Albrecht J. Regulation of $\mathrm{pH}$ in the mammalian central nervous system under normal and pathological conditions: facts and hypotheses. Neurochem Int. 2008;52:905-19.

8. Hamakawa H, Murashita J, Yamada N, Inubushi T, Kato N, Kato T. Reduced intracellular $\mathrm{pH}$ in the basal ganglia and whole brain measured by 31P-MRS in bipolar disorder. Psychiatry Clin Neurosci. 2004;58:82-8.

9. Haarman BC, Riemersma-Van der Lek RF, de Groot JC, Ruhe HG, Klein HC, Zandstra TE, Burger H, Schoevers RA, de Vries EF, Drexhage HA, et al. Neuroinflammation in bipolar disorder-a [(11)C]-(R)-PK11195 positron emission tomography study. Brain Behav Immun. 2014;40:219-25.

10. Mandal PK, Akolkar H, Tripathi M. Mapping of hippocampal pH and neurochemicals from in vivo multi-voxel 31P study in healthy normal young male/female, mild cognitive impairment, and Alzheimer's disease. J Alzheimers Dis. 2012;31 Suppl 3:S75-86

11. Roberts Jr EL, Sick TJ. Aging impairs regulation of intracellular $\mathrm{pH}$ in rat hippocampal slices. Brain Res. 1996;735:339-42.

12. Roberts Jr EL, Chih CP. The influence of age of $\mathrm{pH}$ regulation in hippocampal slices before, during, and after anoxia. J Cereb Blood Flow Metab. 1997;17:560-6.

13. Forester BP, Berlow YA, Harper DG, Jensen JE, Lange N, Froimowitz MP, Ravichandran C, losifescu DV, Lukas SE, Renshaw PF, Cohen BM. Age-related changes in brain energetics and phospholipid metabolism. NMR Biomed. 2010;23:242-50

14. Amor S, Puentes F, Baker D, van der Valk P. Inflammation in neurodegenerative diseases. Immunology. 2010;129:154-69.

15. Fedirko N, Svichar N, Chesler M. Fabrication and use of high-speed, concentric h+- and Ca2+-selective microelectrodes suitable for in vitro extracellular recording. J Neurophysiol. 2006;96:919-24.

16. Krnjevic K, Walz W. Acidosis and blockade of orthodromic responses caused by anoxia in rat hippocampal slices at different temperatures. J Physiol. 1990;422:127-44.

17. Okada Y, Muckenhoff K, Holtermann G, Acker H, Scheid P. Depth profiles of $\mathrm{pH}$ and $\mathrm{PO} 2$ in the isolated brain stem-spinal cord of the neonatal rat. Respir Physiol. 1993;93:315-26.

18. Torgerson CS, Gdovin MJ, Kogo N, Remmers JE. Depth profiles of pH and $\mathrm{PO} 2$ in the in vitro brainstem preparation of the tadpole Rana catesbeiana. Respir Physiol. 1997;108:205-13.

19. Murphy R, Cherny W, Morgan D, DeCoursey TE. Voltage-gated proton channels help regulate $\mathrm{pHi}$ in rat alveolar epithelium. Am J Physiol Lung Cell Mol Physiol. 2005;288:L398-408.

20. Skelly DT, Hennessy E, Dansereau MA, Cunningham C. A systematic analysis of the peripheral and CNS effects of systemic LPS, IL-1beta, [corrected] TNFalpha and IL-6 challenges in C57BL/6 mice. PLoS One. 2013;8:e69123.

21. Williams AJ, Wei HH, Dave JR, Tortella FC. Acute and delayed neuroinflammatory response following experimental penetrating ballistic brain injury in the rat. J Neuroinflammation. 2007:4:17.

22. Hammes GG. Multiple conformational changes in enzyme catalysis. Biochemistry. 2002:41:8221-8.

23. Makani S, Chen HY, Esquenazi S, Shah GN, Waheed A, Sly WS, Chesler M. NMDA receptor-dependent afterdepolarizations are curtailed by carbonic anhydrase 14: regulation of a short-term postsynaptic potentiation. J Neurosci. 2012;32:16754-62.

24. Traynelis SF, Cull-Candy SG. Proton inhibition of N-methyl-D-aspartate receptors in cerebellar neurons. Nature. 1990;345:347-50.

25. Pasternack M, Smirnov S, Kaila K. Proton modulation of functionally distinct GABAA receptors in acutely isolated pyramidal neurons of rat hippocampus. Neuropharmacology. 1996:35:1279-88.

26. Wilkins ME, Hosie AM, Smart TG. Proton modulation of recombinant GABA(A) receptors: influence of GABA concentration and the beta subunit TM2-TM3 domain. J Physiol. 2005;567:365-77.

27. Wolosker H, Rocha JB, Engelender S, Panizzutti R, De Miranda J, de Meis L. Sarco/endoplasmic reticulum Ca2+-ATPase isoforms: diverse responses to acidosis. Biochem J. 1997;321(Pt 2):545-50.

28. Pick U, Karlish SJ. Regulation of the conformation transition in the CaATPase from sarcoplasmic reticulum by $\mathrm{pH}$, temperature, and calcium ions. J Biol Chem. 1982;257:6120-6.

29. Tombaugh GC, Somjen GG. Effects of extracellular pH on voltage-gated $\mathrm{Na}+, \mathrm{K}+$ and Ca2+ currents in isolated rat CA1 neurons. J Physiol. 1996;493(Pt 3):719-32.

30. Tombaugh GC, Somjen GG. Differential sensitivity to intracellular pH among high- and low-threshold Ca2+ currents in isolated rat CA1 neurons. J Neurophysiol. 1997;77:639-53.
31. Waldmann R, Champigny G, Bassilana F, Heurteaux C, Lazdunski M. A proton-gated cation channel involved in acid-sensing. Nature. 1997;386:173-7.

32. Moody Jr W. Effects of intracellular $\mathrm{H}+$ on the electrical properties of excitable cells. Annu Rev Neurosci. 1984;7:257-78.

33. Bonnet $\mathrm{U}$, Bingmann $\mathrm{D}$, Wiemann M. Intracellular $\mathrm{pH}$ modulates spontaneous and epileptiform bioelectric activity of hippocampal CA3neurones. Eur Neuropsychopharmacol. 2000;10:97-103.

34. Xiong ZQ, Saggau P, Stringer JL. Activity-dependent intracellular acidification correlates with the duration of seizure activity. J Neurosci. 2000;20:1290-6.

35. Bonnet $\mathrm{U}$, Leniger T, Wiemann M. Moclobemide reduces intracellular $\mathrm{pH}$ and neuronal activity of CA3 neurones in guinea-pig hippocampal slices-implication for its neuroprotective properties. Neuropharmacology. 2000;39:2067-74.

36. Bonnet $U$, Leniger $\mathrm{T}$, Wiemann M. Alteration of intracellular $\mathrm{pH}$ and activity of CA3-pyramidal cells in guinea pig hippocampal slices by inhibition of transmembrane acid extrusion. Brain Res. 2000;872:116-24.

37. Leniger $T$, Wiemann $M$, Bingmann $D$, Widman $G$, Hufnagel $A$, Bonnet $U$. Carbonic anhydrase inhibitor sulthiame reduces intracellular $\mathrm{pH}$ and epileptiform activity of hippocampal CA3 neurons. Epilepsia. 2002;43:469-74.

38. Moody Jr W. Appearance of calcium action potentials in crayfish slow muscle fibres under conditions of low intracellular pH. J Physiol. 1980;302:335-46.

39. Stubbs M, McSheehy PM, Griffiths JR, Bashford CL. Causes and consequences of tumour acidity and implications for treatment. Mol Med Today. 2000;6:15-9.

40. Adler $\mathrm{S}$, Simplaceanu $\mathrm{V}, \mathrm{Ho} \mathrm{C}$. Brain $\mathrm{pH}$ in acute isocapnic metabolic acidosis and hypoxia: a 31P-nuclear magnetic resonance study. Am J Physiol. 1990;258:F34-40.

41. Chesler M. Failure and function of intracellular $\mathrm{pH}$ regulation in acute hypoxic-ischemic injury of astrocytes. Glia. 2005;50:398-406.

42. Niesman IR, Schilling JM, Shapiro LA, Kellerhals SE, Bonds JA, Kleschevnikov AM, Cui W, Voong A, Krajewski S, Ali SS, et al. Traumatic brain injury enhances neuroinflammation and lesion volume in caveolin deficient mice. J Neuroinflammation. 2014;11:39.

43. Kato T, Murashita J, Kamiya A, Shioiri T, Kato N, Inubushi T. Decreased brain intracellular pH measured by 31P-MRS in bipolar disorder: a confirmation in drug-free patients and correlation with white matter hyperintensity. Eur Arch Psychiatry Clin Neurosci. 1998;248:301-6.

44. Cerbai F, Lana D, Nosi D, Petkova-Kirova P, Zecchi S, Brothers HM, Wenk GL, Giovannini MG. The neuron-astrocyte-microglia triad in normal brain ageing and in a model of neuroinflammation in the rat hippocampus. PLoS One. 2012;7:e45250

45. Franceschi C. Inflammaging as a major characteristic of old people: can it be prevented or cured? Nutr Rev. 2007;65:S173-176.

46. Colasanti A, Guo Q, Giannetti P, Wall MB, Newbould RD, Bishop C, Onega M, Nicholas R, Ciccarelli O, Muraro PA, et al. Hippocampal neuroinflammation, functional connectivity, and depressive symptoms in multiple sclerosis. Biol Psychiatry. 2016;80(1):62-72.

47. Bonnet U, Bingmann D, Wiltfang J, Scherbaum N, Wiemann M. Modulatory effects of neuropsychopharmaca on intracellular pH of hippocampal neurones in vitro. Br J Pharmacol. 2010;159:474-83.

48. Svichar N, Esquenazi S, Chen HY, Chesler M. Preemptive regulation of intracellular pH in hippocampal neurons by a dual mechanism of depolarization-induced alkalinization. J Neurosci. 2011;31:6997-7004.

49. Roberts Jr EL, He J, Chih CP. The influence of glucose on intracellular and extracellular $\mathrm{pH}$ in rat hippocampal slices during and after anoxia. Brain Res. 1998;783:44-50.

50. Di Filippo M, Chiasserini D, Tozzi A, Picconi B, Calabresi P. Mitochondria and the link between neuroinflammation and neurodegeneration. J Alzheimers Dis. 2010;20 Suppl 2:S369-379.

51. Poyton RO, Ball KA, Castello PR. Mitochondrial generation of free radicals and hypoxic signaling. Trends Endocrinol Metab. 2009;20:332-40.

52. Fukui $\mathrm{H}$, Moraes $\mathrm{CT}$. The mitochondrial impairment, oxidative stress and neurodegeneration connection: reality or just an attractive hypothesis? Trends Neurosci. 2008:31:251-6.

53. Errea O, Moreno B, Gonzalez-Franquesa A, Garcia-Roves PM, Villoslada P. The disruption of mitochondrial axonal transport is an early event in neuroinflammation. J Neuroinflammation. 2015;12:152.

54. Viviani B, Bartesaghi S, Gardoni F, Vezzani A, Behrens MM, Bartfai T, Binaglia M, Corsini E, Di Luca M, Galli CL, Marinovich M. Interleukin-1beta enhances NMDA receptor-mediated intracellular calcium increase through activation of the Src family of kinases. J Neurosci. 2003;23:8692-700. 
55. Liu Y, Kintner DB, Chanana V, Algharabli J, Chen X, Gao Y, Chen J, Ferrazzano P, Olson JK, Sun D. Activation of microglia depends on $\mathrm{Na}+/ \mathrm{H}+$ exchange-mediated $\mathrm{H}+$ homeostasis. J Neurosci. 2010;30:15210-20.

56. Shi Y, Chanana V, Watters JJ, Ferrazzano P, Sun D. Role of sodium/hydrogen exchanger isoform 1 in microglial activation and proinflammatory responses in ischemic brains. J Neurochem. 2011;119:124-35.

57. Lagadic-Gossmann D, Huc L, Lecureur V. Alterations of intracellular pH homeostasis in apoptosis: origins and roles. Cell Death Differ. 2004;11:953-61.

58. Ishisaka R, Utsumi T, Kanno T, Arita K, Katunuma N, Akiyama J, Utsumi K. Participation of a cathepsin L-type protease in the activation of caspase-3. Cell Struct Funct. 1999;24:465-70.

59. Barry MA, Eastman A. Endonuclease activation during apoptosis: the role of cytosolic Ca2+ and pH. Biochem Biophys Res Commun. 1992;186:782-9.

60. Schneider D, Gerhardt E, Bock J, Muller MM, Wolburg H, Lang F, Schulz JB. Intracellular acidification by inhibition of the $\mathrm{Na}+\mathrm{H}+$-exchanger leads to caspase-independent death of cerebellar granule neurons resembling paraptosis. Cell Death Differ. 2004:11:760-70.

61. Lam TI, Brennan-Minnella AM, Won SJ, Shen Y, Hefner C, Shi Y, Sun D, Swanson RA. Intracellular pH reduction prevents excitotoxic and ischemic neuronal death by inhibiting NADPH oxidase. Proc Natl Acad Sci U S A. 2013;110:E4362-4368.

62. Berthet C, Lei H, Thevenet J, Gruetter R, Magistretti PJ, Hirt L. Neuroprotective role of lactate after cerebral ischemia. J Cereb Blood Flow Metab. 2009;29:1780-9.

63. Bozzo L, Puyal J, Chatton JY. Lactate modulates the activity of primary cortical neurons through a receptor-mediated pathway. PLoS One. 2013;8:e71721.

\section{Submit your next manuscript to BioMed Central and we will help you at every step:}

- We accept pre-submission inquiries

- Our selector tool helps you to find the most relevant journal

- We provide round the clock customer support

- Convenient online submission

- Thorough peer review

- Inclusion in PubMed and all major indexing services

- Maximum visibility for your research

Submit your manuscript at www.biomedcentral.com/submit 